\title{
Characterization of Tissue Distribution, Catabolism, and Elimination of an Anti-Staphylococcus aureus THIOMAB Antibody-Antibiotic Conjugate in Rats ${ }^{\mathbb{S}}$
}

\author{
[1 Hao Cai, ${ }^{1}$ Victor Yip, ${ }^{1}$ M. Violet Lee, Sylvia Wong, Ola Saad, Shuguang Ma, Nina Ljumanovic, \\ S. Cyrus Khojasteh, Amrita V. Kamath, and Ben-Quan Shen
}

\begin{abstract}
Preclinical and Translational Pharmacokinetics and Pharmacodynamics (H.C., V.Y., A.V.K., B.-Q.S.), BioAnalytical Sciences (M.V.L., S.W., O.S.), Drug Metabolism and Pharmacokinetics (S.M., S.C.K.), and Safety Assessment (N.L.), Genentech Inc., South San Francisco, California
\end{abstract}

Received April 22, 2020; accepted August 10, 2020

\begin{abstract}
Invasive Staphylococcus aureus infection is a leading cause of infectious disease-related deaths because $S$. aureus survives within host phagocytic cells, from which the bacteria are not adequately eliminated using current antibiotic treatments. Anti-S. aureus THIOMAB antibody-antibiotic conjugate (TAC), an anti-S. aureus antibody conjugated with antibiotic payload dmDNA31, was designed to deliver antibiotics into phagocytes, thereby killing intracellular $S$. aureus. Herein, we present the distribution, metabolism/catabolism, and elimination properties for this modality. The tissue distribution of TAC and the release and elimination of its payload dmDNA31 were characterized in rats using multiple approaches. Intravenous injection of unconjugated $\left[{ }^{14} \mathrm{C}\right] \mathrm{dmDNA31}$ to rats resulted in a rapid clearance in both systemic circulation and tissues, with biliary secretion as the major route of elimination. Six major metabolites were identified. When $\left[{ }^{14} \mathrm{C}\right] \mathrm{dmDNA31}$ was conjugated to an antibody as TAC and administered to rat intravenously, a sustained exposure was observed in both systemic circulation and tissues. The dmDNA31 in blood and tissues mainly remained in conjugated form after administering TAC, although minimal deconjugation of dmDNA31 from TAC was also observed. Several TAC catabolites
\end{abstract}

were identified, which were mainly eliminated through the biliaryfecal route, with dmDNA31 and deacetylated dmDNA31 as the most abundant catabolites. In summary, these studies provide a comprehensive characterization of the distribution, metabolism/catabolism, and elimination properties of TAC. These data fully support further clinical development of TAC for the invasive and difficult-to-treat S. aureus infection.

\section{SIGNIFICANCE STATEMENT}

The present studies provide a comprehensive investigation of the absorption, distribution, metabolism/catabolism, and elimination of the first antibody-antibiotic conjugate developed for the treatment of an infectious disease. Although many antibody-drug conjugates are in development for various disease indications, only a limited amount of absorption, distribution, metabolism/catabolism, and elimination information is available in the literature. This study demonstrates the use of radiolabeling technology to delineate the absorption, distribution, metabolism/catabolism, and elimination properties of a complex modality and help address the key questions related to clinical pharmacological studies.

\section{Introduction}

Staphylococcus aureus is a leading cause of death-related bacterial infections (van Hal et al., 2012; Bassetti et al., 2018). Patients with invasive $S$. aureus infections exhibit severe complications, including infective endocarditis, pyelonephritis, and osteomyelitis (Levine et al., 1991; Fowler et al., 2007; Archer et al., 2011). Current standard-of-care antibiotics exhibit a relatively high failure rate in the treatment of invasive $S$. aureus infection (Liu et al., 2011; Daghighi et al., 2015), with the main challenge being the internalization and survival of these

This work was supported by Genentech Inc.

${ }^{1}$ H.C. and V.Y. contributed equally to this work.

All the authors are current employees of Genentech Inc.

https://doi.org/10.1124/dmd.120.000092.

SThis article has supplemental material available at dmd.aspetjournals.org. bacteria within phagocytes. $S$. aureus bacteria, which reside inside the phagocytes, not only establish an intracellular reservoir that enables further spread but also lead to resistance to standard-of-care antibiotics. Therefore, a much higher extracellular concentration of antibiotics is needed to kill intracellular $S$. aureus bacteria than planktonic bacteria (Barcia-Macay et al., 2006; Fowler et al., 2007; Thwaites and Gant, 2011).

To overcome this challenge of treating invasive $S$. aureus bacterial infection, anti-S. aureus THIOMAB antibody-antibiotic conjugate (TAC) was developed to specifically kill $S$. aureus within phagocytes (Lehar et al., 2015). TAC was generated by using a protease cleavable valine-citrulline (val-cit) linker (Junutula et al., 2008) to conjugate dmDNA31 to a monoclonal human IgG1 antibody that specifically binds to teichoic acids (a cell wall antigen) of $S$. aureus (i.e., anti-S. aureus antibody). The antibiotic dmDNA31 is a novel drug against methicillin-resistant $S$. aureus. TAC can bind to bacteria in systemic

ABBREVIATIONS: ADC, antibody-drug conjugate; DDI, drug-drug interaction; dmDNA31, 4-dimethylamino piperidino-hydroxybenzoxazinorifamycin; hlgG1, human hlgG1; P-gp, permeability glycoprotein; PK, pharmacokinetics; TAC, anti-Staphylococcus aureus; THIOMAB, antibodyantibiotic conjugate. 
circulation and tissues and facilitate the uptake of bacteria into phagocytes through opsonization. In the phagolysosome, the linker is cleaved by proteases such as cathepsin B, and active dmDNA31 is released to kill both TAC-bound and pre-existing bacteria in the phagocytes. Although dmDNA31 can be nonspecifically taken up into target cells, a higher intracellular antibiotic concentration in the phagocytes is achieved when dmDNA31 is conjugated to anti-S. aureus antibody as a result of target engagement and the subsequent antibody opsonization. In previous studies, the systemic pharmacokinetics (PK) and pharmacodynamics of TAC were evaluated in different preclinical models (Deng et al., 2019). Single administration of TAC significantly reduced the bacterial load in kidney and heart from severe combined immunodeficiency mice infected with $S$. aureus bacteria (Zhou et al., 2016). A dose-dependent and sustained suppression of bacterial growth was also observed via whole-body imaging using a bioluminescent mouse model (Zhou et al., 2019).

Because of the complex structure of TAC and its unique mechanism of action, the characterization of the drug's distribution, metabolism/ catabolism, and elimination properties was necessary to support its clinical development. Similar to other antibody-drug conjugates (ADCs) for cancer treatment (Shen et al., 2012), the antibody component of TAC binds to $S$. aureus bacteria but has no direct antibacterial activity. TAC is designed to deliver the antibiotic dmDNA31 into the phagocytes in systemic circulation and infected tissues. Once TAC is internalized, dmDNA31 is released, subsequently killing the bacteria hidden inside the phagocytes. Therefore, the in vivo stability and tissue distribution and accumulation of TAC significantly affects the efficacy and safety of the molecule in patients. In addition, understanding the release, metabolism/catabolism, and elimination routes of payload dmDNA31 will help assess the risk of drug-drug interactions (DDIs), inform on the necessity of analyzing patients' metabolic profiles, and evaluate the need for conducting special population studies in patients with hepatic or renal impairment.

In this study, we used radiolabeling technology to track different components of TAC. This method allowed us to answer key questions related to linker stability, catabolism (defined as the degradation of TAC from its antibody or small-molecule components through lysosomal degradation or linker cleavage), metabolism (defined as the processes by which the low-molecular-weight cytotoxic drug is chemically modified by enzymes in the body), distribution, and elimination of TAC in rats. The antibody component of TAC was labeled with ${ }^{111}$ In or ${ }^{125} \mathrm{I}$. The catabolites of antibodies labeled with metal radionuclides (i.e., ${ }^{111} \mathrm{In}$ ) are trapped inside cells as a result of residualizing properties of this charged, highly polar probe (Boswell et al., 2013). In contrast, the radiohalogens (i.e., ${ }^{125}$ I) can be released outside the cells after antibody catabolism. The combination of residualizing ${ }^{111} \mathrm{In}$ and nonresidualizing ${ }^{125}$ I enabled us to evaluate the distribution, catabolism, and potential accumulation of TAC in different tissues (Pastuskovas et al., 2012; Kamath et al., 2014). ${ }^{14} \mathrm{C}$-labeled dmDNA31 was then either conjugated to the antibody to make TAC or used alone to assess its distribution, deconjugation, metabolism/catabolism, and elimination. Data from these studies fully support further clinical development of TAC for treating $S$. aureus infections.

\section{Material and Methods}

Radiochemistry. $\quad\left[{ }^{14} \mathrm{C}\right] \mathrm{dmDNA} 31$ (lot 7643CAL018-4) and $\left[{ }^{14} \mathrm{C}\right]$ dmDNA31 with val-cit linker (lot 7644CAL001-5) were provided by Selcia Limited (Essex, United Kingdom). $\left[{ }^{14} \mathrm{C}\right] \mathrm{dmDNA} 31$ with a val-cit linker was conjugated to the anti-S. aureus antibody to generate $\left[{ }^{14} \mathrm{C}\right] \mathrm{TAC}$ with a drugto-antibody ratio of 1.6 (Supplemental Fig. 1). This conjugation method was described in a previous publication (Junutula et al., 2008). The radiolabeling of TAC with ${ }^{125}$ I or ${ }^{111}$ In was performed at Genentech Inc. TAC was conjugated to $1,4,7,10$-tetraazacyclododecane- $N, N^{\prime}, N^{\prime \prime}, N^{\prime \prime \prime}$ tetraacetic acid for ${ }^{111} \mathrm{In}$ complexation by random modification of lysine residues as previously described (Boswell et al., 2013). ${ }^{125}$ I-labeled antibodies were radioiodinated using an indirect iodogen addition method established by Chizzonite et al. (1991).

Animal Housing and Procedure. The biodistribution of radiolabeled TAC was evaluated in both male and female rats since no significant difference in systemic PK was observed between the two sexes (data not shown). All animal studies were performed in the Genentech animal facility accredited by the Association for Assessment and Accreditation of Laboratory Animal Care International. All the protocols and procedures for animal studies were approved by Genentech Institutional Animal Care and Use Committee and performed in accordance with institutional and regulatory guidelines. Rats in mass balance studies were kept in special metabolic cages (Laboratory Products Inc., Maywood, $\mathrm{NJ})$. No special housing conditions were given for the animals in other studies. All the personnel involved in animal experiments were trained according to institutional animal care and use committee guidelines.

Systemic PK, Metabolism, and Mass Balance Studies with $\left[{ }^{14} \mathrm{C}\right] \mathrm{dmDNA31}$ in Rats. Nine jugular vein-, femoral vein-, and bile duct-cannulated 6- to 8-weekold male Sprague-Dawley rats $(\sim 250 \mathrm{~g})$ were purchased from Charles River Laboratories (Hollister, CA). Each animal was given an intravenous bolus of $2 \mathrm{mg} / \mathrm{kg}$ $\left[{ }^{14} \mathrm{C}\right] \mathrm{dmDNA} 31$ (radioactivity of $113.4 \mu \mathrm{Ci} / \mathrm{kg}$ in $500 \mu \mathrm{l} \mathrm{PBS}$ ). Blood samples $(\sim 0.3 \mathrm{ml})$ were collected from jugular cannula at $2,5,10,30$, and 45 minutes and then at 1, 3, 6, 24, and 72 hours after intravenous administration. To obtain plasma, blood was deposited into lithium heparin tubes, gently inverted several times to properly mix the anticoagulant, and centrifuged at $11,000 \mathrm{rpm}$ for 5 minutes at $4^{\circ} \mathrm{C}$. Bile was sampled through the bile duct cannulation from animals. Urine and feces were collected from the metabolic cages at $0-3,3-6,6-10,10-24,24-32,32-48,48-56$, and 56-72 hours postinjection. After each collection of urine and feces, the cages were rinsed with $10 \mathrm{ml}$ of 50:50 methanol/water to remove any trace contaminant from previous collections. Plasma, urine, and feces samples were kept frozen at $-80^{\circ} \mathrm{C}$ before analyses.

At 1, 24, and 72 hours after drug administration, three out of the nine animals were euthanized by exsanguination under anesthesia for tissue collection. Approximately $0.2 \mathrm{~g}$ of tissue samples from different organs (e.g., liver, heart, kidney, lung, etc.) were collected and lysed in the scintillation vials using methods described previously (Boswell et al., 2013). Total radioactivity of processed samples was measured using a TriCarb TR2900 liquid scintillation analyzer (PerkinElmer, Billerica, MA).

Characterization of $\left[{ }^{14} \mathbf{C}\right] \mathbf{d m D N A 3 1}$ Metabolites in Bile and Urine. Bile and urine samples were pooled across time points that cover more than $90 \%$ of the radioactivity excreted in that route and injected into an Accela ultra performance liquid chromatography coupled with an LTQ-orbitrap Velos system (Thermo Scientific, San Jose, CA) and an online $\beta$-RAM 5C radiodetector (Laboratory Logics, Tampa, FL) for radioprofiling. Chromatographic separation was performed on a Luna C18 column $(150 \times 4.6 \mathrm{~mm}, 3-\mu \mathrm{m}$ particle size; Phenomenex, Torrance, CA) with mobile phases A ( $0.1 \%$ formic acid in water) and $\mathrm{B}(0.1 \%$ formic acid in acetonitrile) at a constant flow rate of $1 \mathrm{ml} / \mathrm{min}$. The gradient was as follows: $5 \% \mathrm{~B}$ for 2 minutes; increase to $15 \% \mathrm{~B}$ at 4 minutes, $42 \% \mathrm{~B}$ at 44 minutes, $75 \% \mathrm{~B}$ at 49 minutes, and $95 \% \mathrm{~B}$ at 50 minutes; hold at 95\% B until 55 minutes; decrease to $5 \%$ B at 55.1 minutes; and then allow for column re-equilibration until 60 minutes. The flow was split to $3: 1$ postcolumn for radio measurements and mass spectrometry, respectively. Feces samples were first weighed, combined with a 4-fold volume of water, and homogenized on ice. The aliquots $(200 \mu \mathrm{l})$ were transferred to scintillation vials and further processed using the method described by Shen et al. (2012).

Tissue Distribution Studies with ${ }^{125}$ I or ${ }^{111}$ In Radiolabeled TAC. The 6- to 8 -week-old male Sprague-Dawley rats $(\sim 250 \mathrm{~g})$ were purchased from Charles River Laboratories and given an intravenous bolus dose of the mixture of ${ }^{125} \mathrm{I}$ - or ${ }^{111}$ In-labeled TAC in PBS (radioactivity dose of $80 \mu \mathrm{Ci} / \mathrm{kg}$ for each isotope) in the presence or absence of $50 \mathrm{mg} / \mathrm{kg}$ unlabeled TAC. Tissue samples from different organs (e.g., liver, heart, kidney, lung, etc.) were collected from euthanized animals and processed with the method described above. Total radioactivity of processed samples was measured using a PerkinElmer Wizard2 analyzer (PerkinElmer).

Systemic PK and Tissue Distribution with $\left[{ }^{14} \mathrm{C}\right] \mathrm{TAC}$ in Rats. A total of 12 female Sprague-Dawley rats, each weighing $200 \mathrm{~g}$, were obtained from Charles 
A

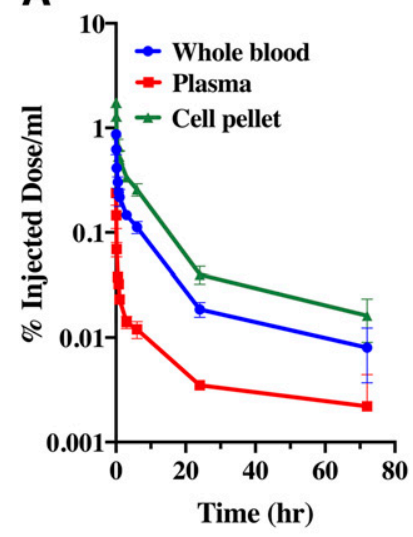

B

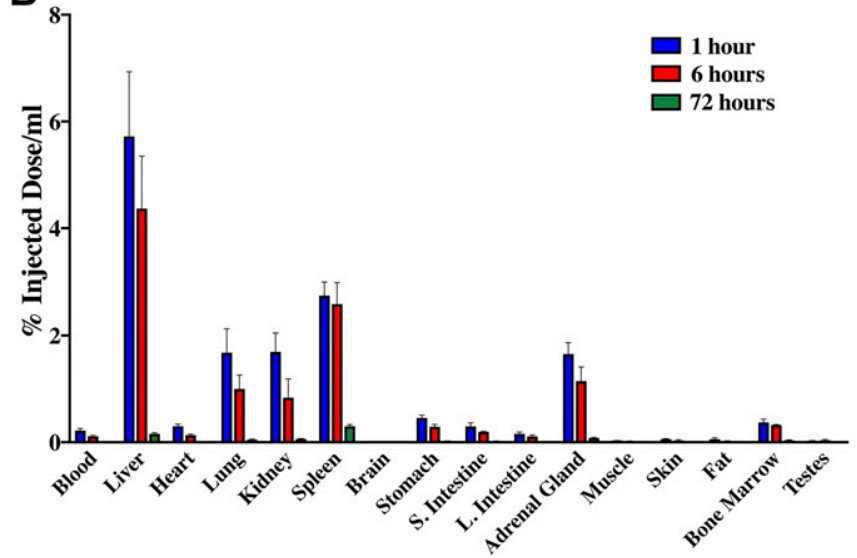

Fig. 1. Systemic PK and tissue biodistribution of unconjugated $\left[{ }^{14} \mathrm{C}\right] \mathrm{dmDNA} 31$ after a single intravenous administration. (A) Radioactivity of $\left[{ }^{14} \mathrm{C}\right] \mathrm{dmDNA} 31$ (as percentage of injected dose per milliliter) from whole blood, plasma, and cell pellets in rats up to 72 hours postadministration. (B) Radioactivity of $\left[{ }^{14} \mathrm{C}\right] \mathrm{dmDNA} 31$ from blood and multiple organs isolated from rats at 1 , 6 , and 72 hours after intravenous administration. Data are represented as means $\pm \mathrm{SD} . N=3$ per time point.
River Laboratories and received a single intravenous bolus dose of $150 \mathrm{mg} / \mathrm{kg}$ of $\left[{ }^{14} \mathrm{C}\right] \mathrm{TAC}$ (equivalent to $74 \mu \mathrm{Ci} / \mathrm{kg}$ radioactivity, in PBS). Blood $(\sim 0.3 \mathrm{ml})$ samples were collected from the tail vein of animals into lithium heparin tubes at $0.25,1$, and 6 hours and then at 1,3,7, and 14 days after drug administration and aliquoted into three tubes to assess radioactivity in blood, plasma/cell pellets, and protein participate. Plasma was isolated from blood via centrifugation at $11,000 \mathrm{rpm}$ for 5 minutes. Isolated plasma and cell pellets were stored at $-80^{\circ} \mathrm{C}$. To prepare soluble and precipitable fractions from blood, acetonitrile with $1 \%$ trifluoroacetic acid (4-fold of the sample volume) was added. The samples were briefly mixed by vortex and then centrifuged for 5 minutes at $15,800 \mathrm{~g}$ to pellet the precipitate. The supernatant was removed and placed in a glass liquid scintillation vial. Then, $200 \mu \mathrm{l}$ of $30 \% \mathrm{H}_{2} \mathrm{O}_{2}$ was added to each sample in 0.1-ml aliquots.

For tissue collection, three out of the 12 animals were euthanized by exsanguination at each time. Tissue samples were collected and lysed based on the method described in a previous publication (Boswell et al., 2013). Protein precipitate and supernatant were generated from the tissue lysate using the method described above. The radioactivity of all tissue and blood samples was evaluated as discussed above using a Tri Carb 2900TR liquid scintillation analyzer (PerkinElmer)

Mass Balance Study with $\left[{ }^{14} \mathrm{C}\right] \mathrm{TAC}$ in Rats. The mass balance study was conducted in six jugular vein- and bile duct-cannulated 6- to 8-week-old female Sprague-Dawley rats $(\sim 200 \mathrm{~g})$ and six noncannulated 6- to 8-week-old female Sprague-Dawley rats $(\sim 200 \mathrm{~g})$. All the animals received an intravenous bolus dose of $150 \mathrm{mg} / \mathrm{kg}\left[{ }^{14} \mathrm{C}\right] \mathrm{TAC}$ (equivalent to $74 \mu \mathrm{Ci} / \mathrm{kg}$ radioactivity in PBS). Bile was collected from cannulated rats at different time points. Urine and feces were obtained from noncannulated rats using the method described above. An equal weight of feces samples was pooled across time intervals for animals. Each pooled feces sample was resuspended with 8 -fold volume of lysis buffer consisting of $1 \times$ protease inhibitor cocktail in PBS and homogenized on ice for 5 minutes. A 1-ml feces homogenate aliquot was subjected to a 4 -fold acetonitrile precipitation. The supernatant was concentrated to dryness and reconstituted in acetonitrile prior to analysis. To quantitatively identify the catabolites of $\left[{ }^{14} \mathrm{C}\right] \mathrm{TAC}$, the processed plasma, bile, urine, and fecal samples were analyzed on LC-MS/MS in conjunction with a radioactivity monitor to facilitate the peak detection as previously described (Shen et al., 2012).

Data Analyses. The percent of injected dose radioactivity was calculated by dividing the sample scintillating (for ${ }^{14} \mathrm{C}$ )/gamma (for ${ }^{125} \mathrm{I}$ and ${ }^{111} \mathrm{In}$ ) count over the dosing solution count and multiplying by $100 \%$. For tissue samples, the scintillating count was normalized by weight. All experiments were performed on biological replicates. Sample size for each experimental group has been reported in the figure legends. The graphs were plotted, and data analyses were performed using Prism (GraphPad Inc., CA).

\section{Results}

Unconjugated dmDNA31 Showed Rapid Clearance from Systemic Circulation and Tissues. The PK of unconjugated dmDNA31 was first assessed after a single intravenous administration of $2 \mathrm{mg} / \mathrm{kg}\left[{ }^{14} \mathrm{C}\right] \mathrm{dmDNA} 31$ into rats. A rapid reduction of the dmDNA31 concentration (reflected by ${ }^{14} \mathrm{C}$ radioactivity) was observed in systemic circulation (Fig. 1A). Radioactivity levels of ${ }^{14} \mathrm{C}$ were almost undetectable in blood at 24 hours postadministration. A 6- to 18 -fold higher level of radioactivity was observed throughout the study in the cell pellets isolated from blood compared with plasma, suggesting a strong partition to red blood cells (Fig. 1A). At 1 hour after intravenous administration, dmDNA31 quickly distributed to multiple organs, such as liver, spleen, and kidney. However, the exposure of unconjugated dmDNA31 in tissues could be maintained only within a short time period, as no remaining radioactivity was detected after 72 hours (Fig. 1B).

Unconjugated dmDNA31 Was Mainly Eliminated through Biliary/Fecal Routes, with Six Major Metabolites Identified from Bile Samples. To understand the elimination mechanism of unconjugated dmDNA31, a mass balance study was performed using bile duct-cannulated rats. At 72 hours after single intravenous administration, $70 \%$ of the injected dose was excreted in bile and feces, whereas $25 \%$ of the injected dose was recovered from urine (Fig. 2A). Six metabolites were identified in the collected bile samples (Fig. 2B). Intact dmDNA31 was the major eliminated species $(34.1 \%$ of total dose recovered in urine and bile). M3 (oxidation), M4 (hydrolysis of the acetate moiety), and M5 (oxidation) coeluted and accounted for $18.3 \%$ and $1.52 \%$ of the injected dose in bile and urine, respectively (Table 1). M1 eluted at the solvent front around the solvent dead volume. Using hydrophilic interaction liquid chromatography, this single peak in Reversed-Phase High-Performance Liquid Chromatography was separated into two peaks. One solvent front peak remained unknown; however, the later peak was identified as $\mathrm{N}, \mathrm{N}$-dimethyl-4-aminopiperidine (data on file). Therefore, M1 is presumably a mixture of $N, N$ dimethyl-4-aminopiperidine and possibly formaldehyde from loss of the ${ }^{14} \mathrm{C}$ label on an $N$-methyl group on dmDNA31 or its downstream metabolite, such as formic acid. M1 was detected mainly in urine and accounted for $9.10 \%$ of the injected dose. M2 was a glutathione conjugate of dmDNA31 and accounted for $4.52 \%$ and $1.49 \%$ of the injected dose in bile and urine, respectively. M6 was identified as the $N$-desmethyl-dmDNA31 metabolite and accounted for $1.57 \%$ of the dose in bile.

TAC Exhibited a Biodistribution Profile Similar to a Typical hIgG1 Antibody. The distribution of TAC was then evaluated via labeling its antibody component with ${ }^{125} \mathrm{I}$ and ${ }^{111} \mathrm{In}$ and its payload component with ${ }^{14} \mathrm{C}$. $\left[{ }^{14} \mathrm{C}\right] \mathrm{TAC}$ showed relatively high stability in the plasma from rats, cynomolgus monkeys, and human (data not shown). After a single intravenous injection of radiolabeled TAC to male rats, TAC showed a tissue distribution profile similar to other typical hIgG1 
A

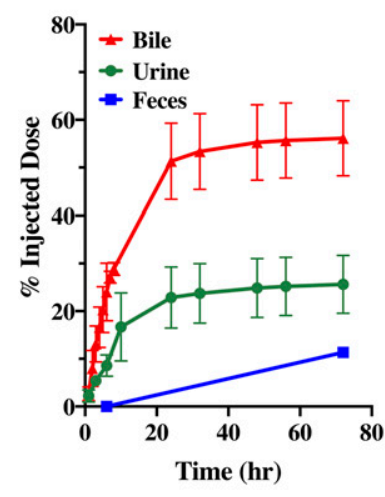

B
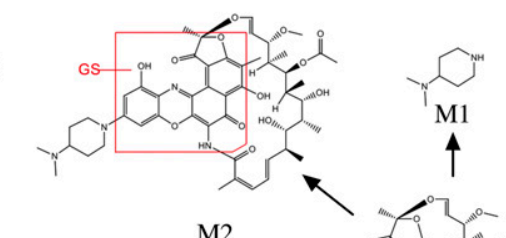

M2

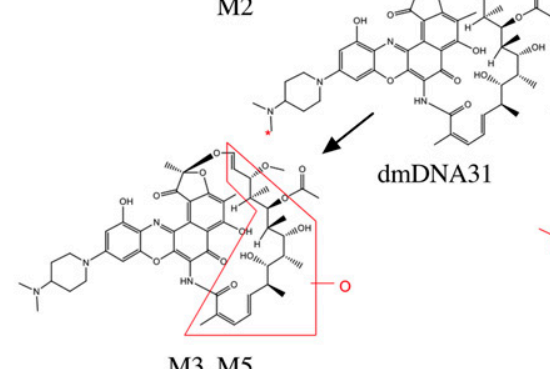

M3, M5

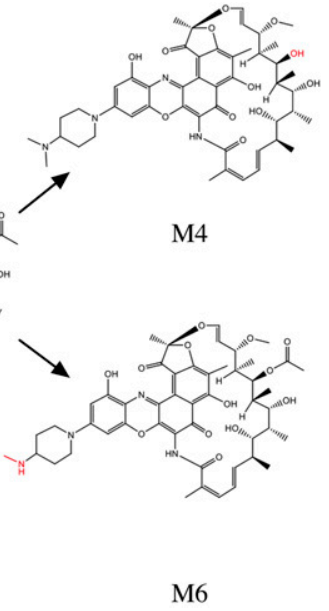

Fig. 2. Mass balance study in cannulated rats after a single intravenous administration of unconjugated $\left[{ }^{14} \mathrm{C}\right] \mathrm{dmDNA} 31$. (A) Total ${ }^{14} \mathrm{C}$ radioactivity in bile, feces, and urine samples collected throughout the study. (B) Structures of dmDNA31 and its metabolites identified in bile samples. M1 is a mixture of different components including $N, N$-dimethyl-4-aminopiperidine (structure shown) and possibly formaldehyde from loss of the ${ }^{14} \mathrm{C}$ label on an $\mathrm{N}$-methyl group on dmDNA31 or its downstream metabolite such as formic acid. Data are represented as means $\pm \mathrm{SD} . N=3$ per time point. antibodies (Deng et al., 2016; Li et al., 2016), with relatively high tissue/ plasma radioactivity ratio observed in well perfused organs, including lung, heart, and kidney (Fig. 3). Similar tissue distribution profiles of TAC were obtained based on ${ }^{125}$ I radioactivity versus ${ }^{111}$ In radioactivity despite a slightly higher partition ratio using ${ }^{111}$ In radioactivity. Compared with radiolabeled TAC alone, no significant change in tissue distribution was observed when radiolabeled TAC was coadministered with $50 \mathrm{mg} / \mathrm{kg}$ unlabeled TAC, suggesting that the tissue distribution of TAC was not saturated (Supplemental Fig. 2).

A Sustained Exposure of Antibody-Conjugated dmDNA31 in Systemic Circulation and Tissue Was Achieved. The systemic PK and tissue distribution of antibody-conjugated $\left[{ }^{14} \mathrm{C}\right] \mathrm{dmDNA} 31$ was assessed via tracking the radioactivity of ${ }^{14} \mathrm{C}$, which was labeled on the dmDNA31 part of TAC (i.e., $\left[{ }^{14}\right.$ C]TAC) (Supplemental Fig. 1B). In contrast to unconjugated dmDNA31, antibody-conjugated dmDNA31 exhibited a more sustained systemic $\mathrm{PK}$ in rats after a single intravenous administration of $150 \mathrm{mg} / \mathrm{kg}\left[{ }^{14} \mathrm{C}\right] \mathrm{TAC}$ and mainly existed in the plasma fraction of the blood instead of in the cell pellet (Fig. 4A). Upon addition of acetonitrile to the plasma samples, over $97 \%$ of the radioactivity was observed in the precipitate fraction, suggesting that the majority of dmDNA31 remained conjugated and precipitated with the antibody (Fig. 4B).

Antibody-conjugated dmDNA31 had a sustained tissue distribution compared with unconjugated $\left[{ }^{14} \mathrm{C}\right] \mathrm{dmDNA} 31$ (Fig. 4C). Conjugated dmDNA31 in tissues reached peak concentrations at 1 or 6 hours after drug administration and was then slowly eliminated. To evaluate any possible release of $\left[{ }^{14} \mathrm{C}\right] \mathrm{dmDNA} 31$ from TAC, total radioactivity of ${ }^{14} \mathrm{C}$ in soluble and precipitated fractions of the tissue homogenate after incubation with acetonitrile was assessed. Although the majority of ${ }^{14} \mathrm{C}$-labeled dmDNA31 was observed in the precipitate fraction, ${ }^{14} \mathrm{C}$ radioactivity in the soluble fraction was detected in all different types of organs but not in plasma (Fig. 4D). Greater dmDNA31 release was observed in some organs, including liver and spleen, compared with other organs. These observations suggested that it is the antibody rather than the payload component that determines the systemic PK and tissue distribution of TAC.

Elimination and Catabolism of TAC. A mass balance study in rats with a single intravenous administration of $150 \mathrm{mg} / \mathrm{kg}\left[{ }^{14} \mathrm{C}\right] \mathrm{TAC}$ was conducted. Biliary/fecal secretion was identified as the major route of elimination for dmDNA31, with $75 \%$ of radioactivity recovered in feces samples (Fig. 5A). Greater than $85 \%$ of the ${ }^{14} \mathrm{C}$ radioactivity recovered in urine/bile/feces was in the acetonitrile soluble fraction (data not shown). In these collected feces and urine samples, a total of seven catabolites of TAC ( $\mathrm{C} 1$ to $\mathrm{C} 7)$ were observed, including dmDNA31 (C7) (Fig. 5B). Unconjugated dmDNA31 (C7) and C6 were the major catabolites in the feces samples, which contributed to $70 \%$ of ${ }^{14} \mathrm{C}$ radioactivity (Table 2 ).

\section{Discussion}

This study used radiolabeling techniques in a systematic approach to answer key questions related to tissue distribution, metabolism/catabolism,

TABLE 1

Abundance of dmDNA31 and its metabolites in urine and bile after a single intravenous administration of unconjugated $\left[{ }^{14} \mathrm{C}\right] \mathrm{dmDNA} 31$ in rats

\begin{tabular}{|c|c|c|c|c|c|c|}
\hline Analytes & Protonated Molecular Formula & $\begin{array}{l}\text { Theoretical } \mathrm{m} / \mathrm{z} \\
\text { for }[\mathrm{M}+\mathrm{H}]^{+}\end{array}$ & $\begin{array}{l}\text { Measured } m / z \\
\text { for }[\mathrm{M}+\mathrm{H}]^{+a}\end{array}$ & $\begin{array}{l}\text { Mass Accuracy } \\
\text { (ppm) }\end{array}$ & $\begin{array}{l}\text { Percentage of ID } \\
\text { in Bile }\end{array}$ & $\begin{array}{l}\text { Percentage of ID } \\
\text { in Urine }\end{array}$ \\
\hline dmDNA31 & $\mathrm{C}_{49}^{14} \mathrm{CH}_{63} \mathrm{~N}_{4} \mathrm{O}_{13}^{+}$ & 929.4419 & 929.4443 & 2.58 & 25.4 & 8.65 \\
\hline $\mathrm{M} 1^{b}$ & $\mathrm{C}_{6}^{14} \mathrm{CH}_{17} \mathrm{~N}_{2}^{+}$ & 131.1419 & 131.1428 & 6.86 & 1.05 & 9.10 \\
\hline Unknown $^{b}$ & NA & NA & NA & NA & & \\
\hline M2 & $\mathrm{C}_{59}^{14} \mathrm{CH}_{78} \mathrm{~N}_{7} \mathrm{O}_{19} \mathrm{~S}^{+}$ & 1234.5100 & 1234.5118 & 1.46 & 4.52 & 1.49 \\
\hline $\mathrm{M}^{c}$ & $\mathrm{C}_{49}^{14} \mathrm{CH}_{63} \mathrm{~N}_{4} \mathrm{O}_{14}^{+}$ & 945.4368 & 945.4397 & 3.07 & 18.3 & 1.52 \\
\hline $\mathrm{M} 4^{c}$ & $\mathrm{C}_{47}^{14} \mathrm{CH}_{61} \mathrm{~N}_{4} \mathrm{O}_{12}^{+}$ & 887.4313 & 887.4332 & 2.14 & & \\
\hline $\mathrm{M}^{c}$ & $\mathrm{C}_{49}^{14} \mathrm{CH}_{63} \mathrm{~N}_{4} \mathrm{O}_{14}^{+}$ & 945.4368 & 945.4397 & 3.07 & & \\
\hline \multirow[t]{2}{*}{$\mathrm{M}^{d}$} & $\mathrm{C}_{49} \mathrm{H}_{61} \mathrm{~N}_{4} \mathrm{O}_{13}^{+}$ & 913.4230 & 913.4257 & 2.96 & 1.57 & ND \\
\hline & $\mathrm{C}_{48}^{14} \mathrm{CH}_{61} \mathrm{~N}_{4} \mathrm{O}_{13}^{+}$ & 915.4262 & 915.4293 & 3.39 & & \\
\hline
\end{tabular}

ID, injected dose; NA, not applicable; ND, not detected.

${ }^{a}$ The $\mathrm{m} / \mathrm{z}$ values reported for dmDNA31 and its metabolites were from the most abundant ion incorporating one ${ }^{14} \mathrm{C}$ -

${ }^{b}$ The radioactive peak at retention time 1.9 min (around the solvent dead volume) is presumably a mixture of M1 and an unknown resulted of the loss of ${ }^{14} \mathrm{C}$ label on $N$-methyl group on dmDNA31.

${ }^{c}$ M3, M4, and M5 coeluted under the current LC-MS conditions; therefore, their abundances (percentage of ID) in urine and bile were combined.

${ }^{d}$ M6 was identified as the $N$-desmethyl-dmDNA31 metabolite, so it was observed at $\mathrm{m} / z 913.4257$ and $\mathrm{m} / z$. 915.4293 at an approximately 1:1 ratio, resulting from the loss of either the ${ }^{14} \mathrm{C}$-labeled methyl or nonlabeled methyl, respectively. 

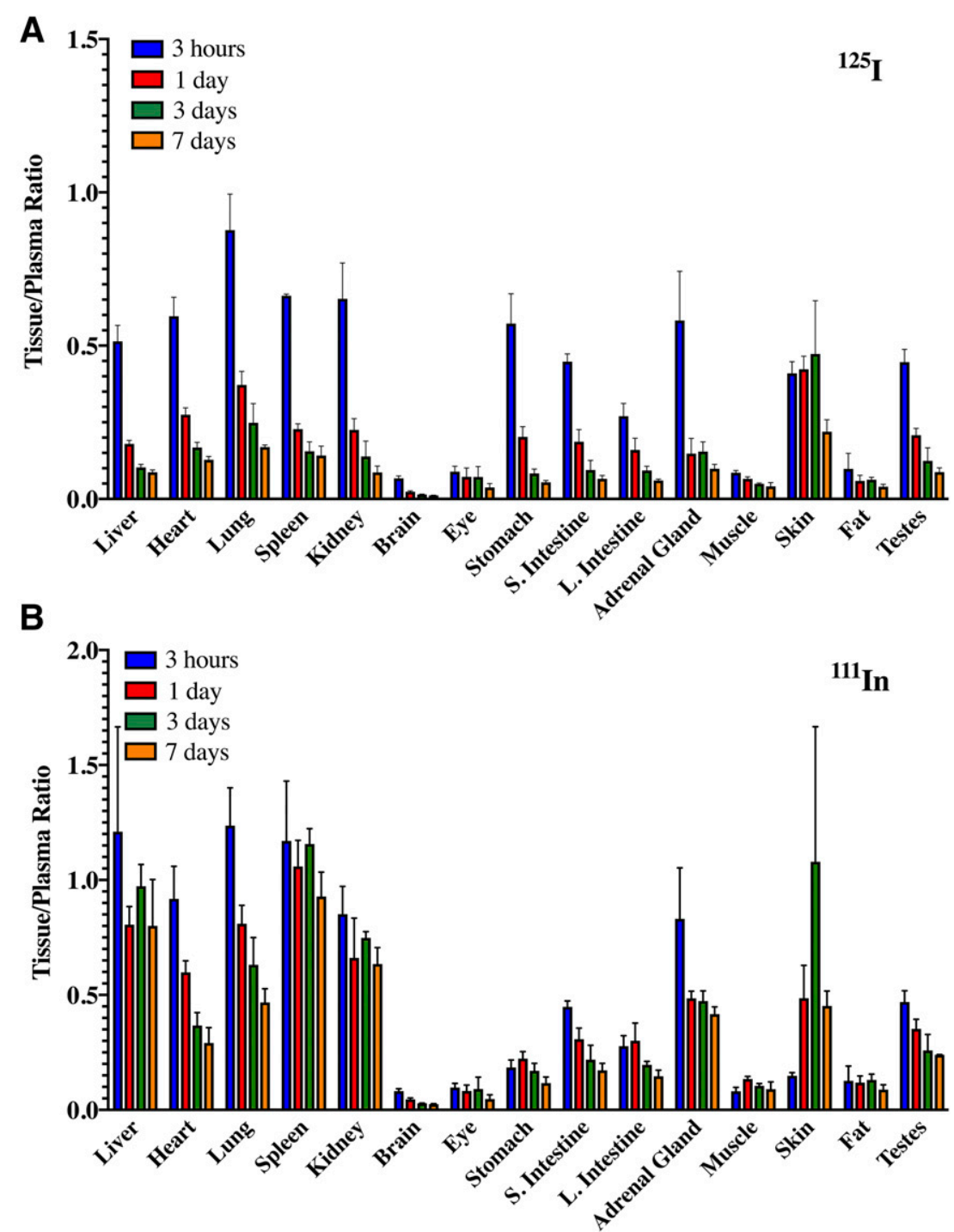

Fig. 3. Tissue biodistribution of radiolabeled TAC in rats after a single intravenous administration. Total radioactivity of (A) ${ }^{125} \mathrm{I}$ and (B) ${ }^{111}$ In in multiple organs from male rats at 3 hours and 1,3 , and 7 days after intravenous administration of a mixture of radiolabeled $\left[{ }^{125} \mathrm{I}\right] \mathrm{TAC}$ and $\left[{ }^{111} \mathrm{In}\right] \mathrm{TAC}$. Data are represented as means $\pm \mathrm{SD} . N=3$ per data point. L. Intestine, large intestine; S. Intestine, small intestine. and elimination of TAC and its antibiotic payload dmDNA31 to support the drug's future clinical development. Since TAC is composed of an antibody conjugated to two payload dmDNA31 molecules, three different radiolabels were used to track different components of TAC. The antibody portion was labeled using ${ }^{125}$ I and ${ }^{111}$ In. Although both isotopes can be used to assess the distribution of TAC into different tissues, only ${ }^{125} \mathrm{I}$ can be released back to extracellular space after the intracellular degradation of the antibody. Side-by-side comparison of the radioactivity from these two isotopes in different tissues not only enabled us to monitor the distribution of TAC but also helped us evaluate its accumulation. Both unconjugated dmDNA31 and antibody-conjugated dmDNA31 were labeled with ${ }^{14} \mathrm{C}$ to evaluate the release and elimination of dmDNA31 and identify any possible metabolites of dmDNA31 and catabolites of the TAC.

Unconjugated dmDNA31 exhibited faster systemic clearance in rats after a single intravenous administration. Although dmDNA31 showed wide distribution in multiple organs, its exposure in the tissues was followed by fast elimination. The major elimination route of intravenously administered dmDNA31 was through biliary secretion of both the parent and its metabolites. In addition to bile samples, radioactivity was also detected in the feces, which is not usually observed in a bile duct-cannulated rat model. This is most likely due to direct secretion of dmDNA31 into feces through the gastrointestinal tract. For example, direct intestinal secretion was observed as a major elimination pathway for apixaban, a substrate of efflux transporters P-gp and/or Breast Cancer Resistance Protein, in rats. About $22 \%$ of the administered dose of apixaban was recovered in the feces after intravenous administration to bile duct-cannulated rats (Zhang et al., 2009). Laffont et al. (2002) demonstrated that intestinal secretion played a greater role than biliary secretion in the overall elimination of ivermectin in rat. Coadministration of the P-gp blocker, verapamil, significantly reduced overall elimination of ivermectin by the small intestine. As dmDNA31 is also a substrate of P-gp ( efflux ratio $=40$ in MDCK-MDR1 cell line, unpublished data), we hypothesize that intestinal secretion might play a minor role in its excretion in rats. Although six metabolites were identified, parent dmDNA31 was still the major species in bile samples, with about $50 \%$ relative abundance. Because of its limited exposure in systemic circulation and tissues, unconjugated dmDNA31 is not an optimal drug for the treatment of invasive $S$. aureus infection.

We then investigated whether sustained tissue exposure of dmDNA31 can be achieved by conjugating dmDNA31 to the anti-S. aureus antibody to generate TAC (Junutula et al., 2008; Lehar et al., 2015). The tissue distribution of ${ }^{125} \mathrm{I}$ - or ${ }^{111} \mathrm{In}$-labeled TAC was similar to the distribution of a typical hIgG1 antibody (Boswell et al., 2013) and was more sustained than unconjugated dmDNA31. A 10\%-30\% tissue/ plasma ${ }^{125}$ I radioactivity ratio was observed in the organs that were 
A

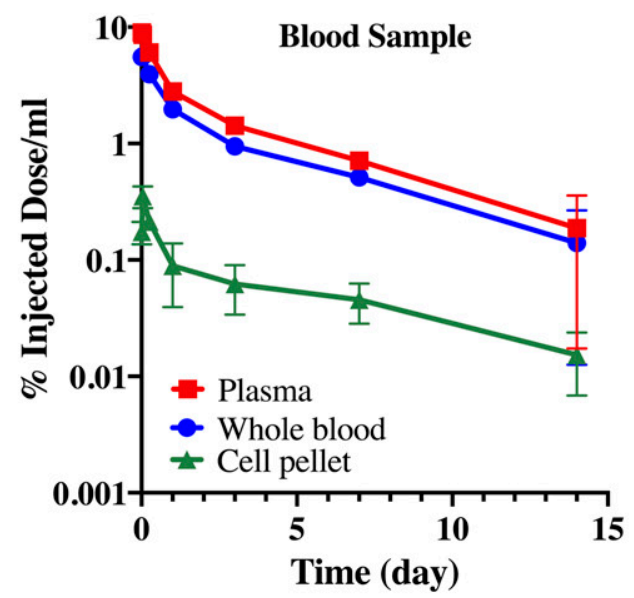

C

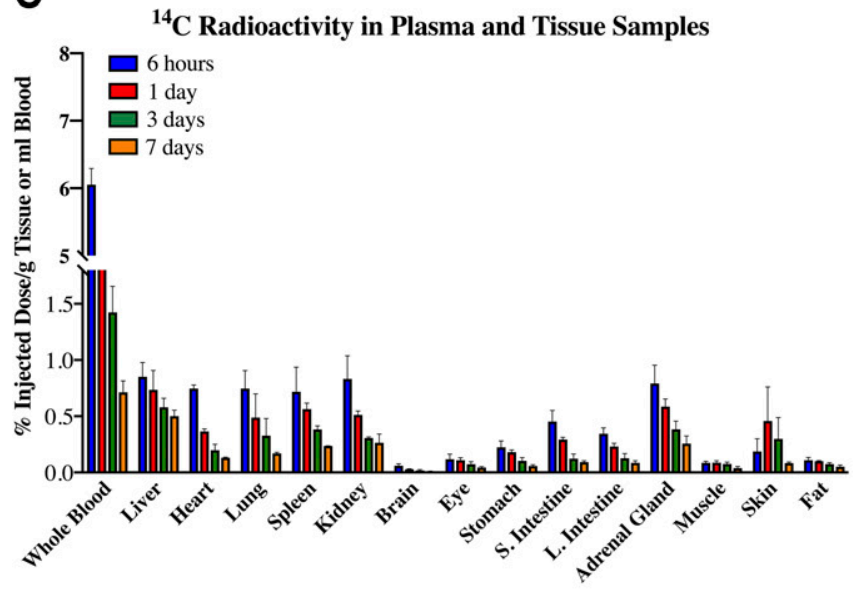

B

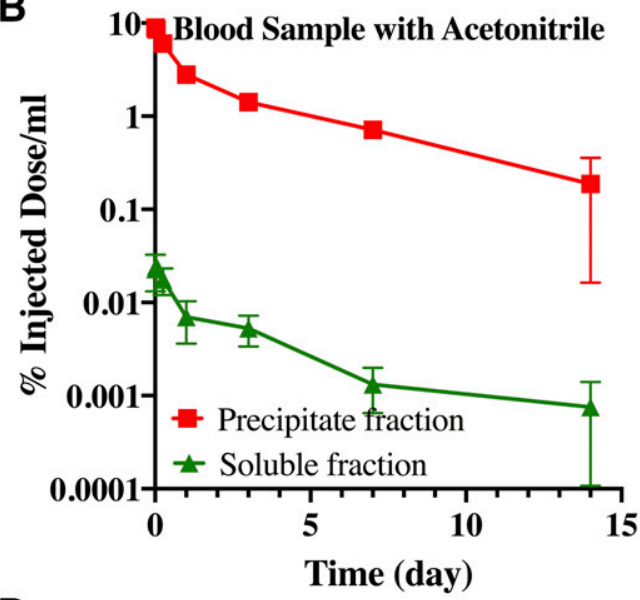

D

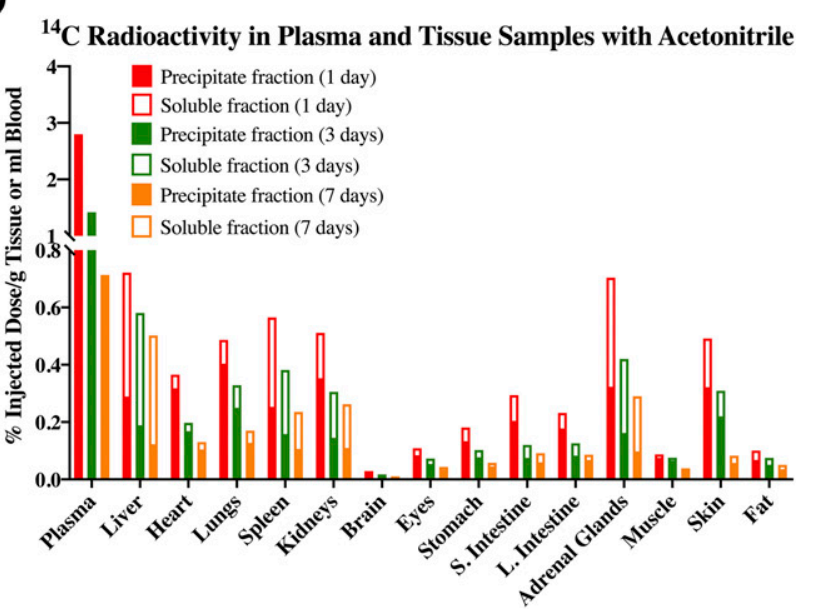

Fig. 4. Systemic PK and tissue distribution of antibody-conjugated dmDNA31. (A) Systemic PK and tissue biodistribution of antibody-conjugated $\left[{ }^{14} \mathrm{C}\right] \mathrm{dmDNA} 31$ after a single intravenous administration. Total radioactivity of ${ }^{14} \mathrm{C}$ from whole blood, plasma, and cell pellets in female rats up to 14 days after intravenous administration. (B) Total radioactivity of ${ }^{14} \mathrm{C}$ in soluble and precipitate fractions from plasma after incubation with acetonitrile. (C) Radioactivity of ${ }^{14} \mathrm{C}$ in multiple organs from rats at 6 hours and 1,3 , and 7 days after intravenous administration of a mixture of radiolabeled $\left[{ }^{14} \mathrm{C}\right] \mathrm{TAC}$ and $150 \mathrm{mg} / \mathrm{kg}$ unlabeled TAC. (D) Radiolabeled activity of dmDNA31 in soluble and precipitate fractions from tissue homogenate postincubation with acetonitrile. Data are represented as means $\pm \mathrm{SD}$. $N=3$ per time point. L. Intestine, large intestine; $\mathrm{S}$. Intestine, small intestine.

relevant to invasive $S$. aureus infection, including kidney, heart, and lung. Consistent with the findings from the use of ${ }^{125} \mathrm{I}$ - or ${ }^{111} \mathrm{In}$-labeled $\mathrm{TAC}$, the radioactivity of ${ }^{14} \mathrm{C}$-labeled dmDNA31 can be detected in plasma and tissues up to 14 days after intravenous administration. Consistent with our understanding of ADCs (Shen et al., 2012), our results show that the distribution of TAC is mainly driven by its antibody

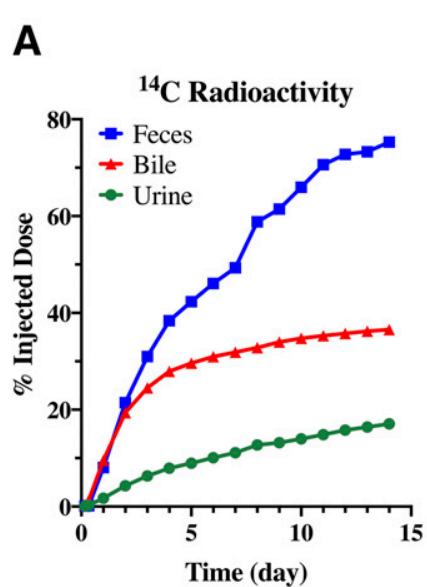

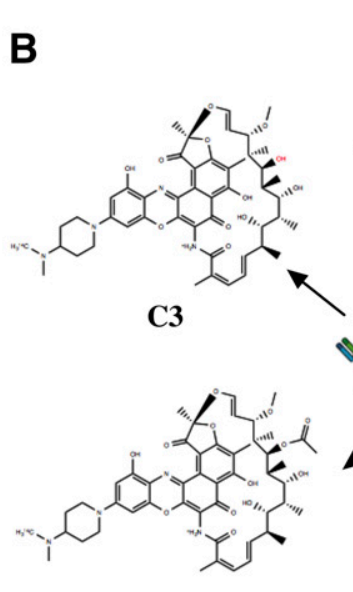

C7
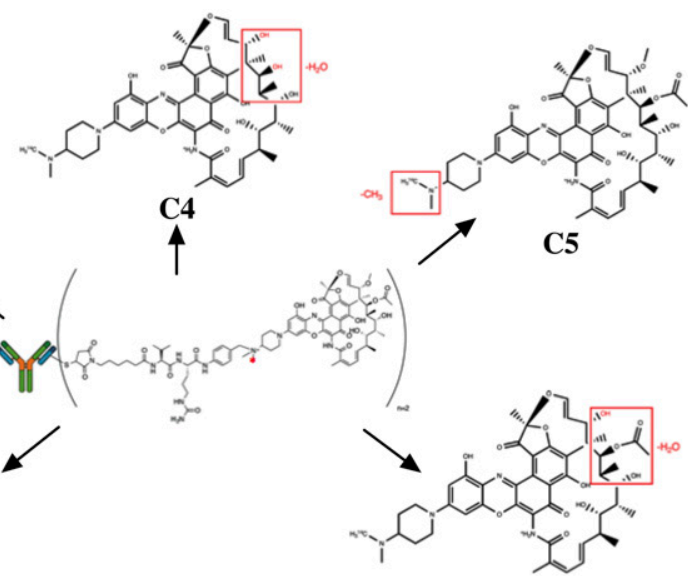

C6

Fig. 5. Mass balance study in rats after single intravenous administration of $\left[{ }^{14} \mathrm{C}\right] \mathrm{TAC}$. (A) Total ${ }^{14} \mathrm{C}$ radioactivity-time profile from bile, feces, and urine samples collected throughout the study. Bile was collected from bile duct-cannulated rats, and feces and urine were collected from noncannulated rats. Data are represented as means \pm SD. $N=3$ per time point. (B) Structure of TAC catabolites detected in plasma, bile, feces, and urine samples. C1 and C2 are unidentified catabolites. 
TABLE 2

Abundance of $\left[{ }^{14} \mathrm{C}\right] \mathrm{TAC}$ catabolites in urine and feces after single intravenous administration of $\left[{ }^{14} \mathrm{C}\right] \mathrm{TAC}$ in rats

\begin{tabular}{|c|c|c|c|c|c|c|}
\hline Analytes & Protonated Molecular Formula & $\begin{array}{l}\text { Theoretical } \mathrm{m} / \mathrm{z} \\
\text { for }[\mathrm{M}+\mathrm{H}]^{+}\end{array}$ & $\begin{array}{l}\text { Measured } m / z \\
\text { for }[\mathrm{M}+\mathrm{H}]^{+a}\end{array}$ & Mass Accuracy (ppm) & $\begin{array}{l}\text { Percentage of ID } \\
\text { in Feces }\end{array}$ & $\begin{array}{l}\text { Percentage of ID } \\
\text { in Urine }\end{array}$ \\
\hline $\mathrm{C} 1$ & NA & NA & NA & NA & ND & 8.34 \\
\hline $\mathrm{C} 2$ & NA & NA & NA & NA & ND & 4.93 \\
\hline $\mathrm{C} 3^{b}$ & $\mathrm{C}_{47}^{14} \mathrm{CH}_{61} \mathrm{~N}_{4} \mathrm{O}_{12}^{+}$ & 887.4313 & 887.4292 & -2.37 & 17.92 & 0.24 \\
\hline $\mathrm{C} 4^{b}$ & $\mathrm{C}_{46}^{14} \mathrm{CH}_{57} \mathrm{~N}_{4} \mathrm{O}_{11}^{+}$ & 855.4051 & 855.4028 & -2.69 & & \\
\hline $\mathrm{C}^{c}$ & $\mathrm{C}_{48}^{14} \mathrm{CH}_{61} \mathrm{~N}_{4} \mathrm{O}_{13}^{+}$ & 915.4262 & 915.4286 & 2.62 & NA & 0.25 \\
\hline $\mathrm{C} 6^{d}$ & $\mathrm{C}_{48}^{14} \mathrm{CH}_{59} \mathrm{~N}_{4} \mathrm{O}_{12}^{+}$ & 897.4156 & 897.4138 & -2.01 & 41.36 & 0.32 \\
\hline $\mathrm{C} 7^{d}$ & $\mathrm{C}_{49}^{14} \mathrm{CH}_{63} \mathrm{~N}_{4} \mathrm{O}_{13}^{+}$ & 929.4419 & 929.4396 & -2.47 & & \\
\hline
\end{tabular}

ID, injected dose; NA, not applicable; ND, not detected.

${ }^{a}$ The $\mathrm{m} / \mathrm{z}$ values reported for dmDNA31 and its metabolites were from the most abundant ion incorporating one ${ }^{14} \mathrm{C}$ -

${ }^{b}$ Catabolites $\mathrm{C} 3$ and $\mathrm{C} 4$ share the same retention time.

${ }^{c} \mathrm{C} 5$ was identified as the $N$-desmethyl-dmDNA31 metabolite, so it was observed at $\mathrm{m} / \mathrm{z} 913.4218$ and $\mathrm{m} / \mathrm{z} 915.4286$ at an approximately $1: 1$ ratio, resulting from the loss of either the ${ }^{14} \mathrm{C}$-labeled methyl or nonlabeled methyl, respectively.

${ }^{d}$ Catabolites C6 and C7 share the same retention time.

component and that this antibody-antibiotic conjugate is a feasible approach to achieve sustained delivery of the antibiotic to tissues. The data also suggest that sex has no apparent impact on the distribution of the molecules.

Since TAC is designed to release its payload in the phagosome, its stability needs to be maintained in the systemic circulation and extracellular space in tissues. The deconjugation of $\left[{ }^{14} \mathrm{C}\right] \mathrm{dmDNA} 31$ from the antibody was evaluated by measuring ${ }^{14} \mathrm{C}$ radioactivity in the soluble fraction of samples after incubating the plasma and tissue homogenate with acetonitrile, as antibody-conjugated dmDNA31 would precipitate along with the antibody. No unconjugated $\left[{ }^{14} \mathrm{C}\right] \mathrm{dmDNA} 31$ was observed in systemic circulation in the blood by 14 days after drug administration. In contrast, slow deconjugation of dmDNA31 was observed in tissues, although the majority of dmDNA31 still remained in conjugated form. Since intracellular accumulation of TAC in tissues was observed in this study, the deconjugation of dmDNA31 from TAC could be due to nonspecific uptake into the phagocytes, the subsequent cleavage of the valcit linker, and the release of dmDNA31 in the phagosome. Results from this study showed that TAC is generally stable in preclinical models.

The metabolism and elimination of antibody-conjugated dmDNA31 (administered as TAC) was systematically investigated. Consistent with unconjugated dmDNA31, approximately $90 \%$ radioactivity of ${ }^{14} \mathrm{C}$ was recovered in bile/feces samples after single intravenous administration of $\left[{ }^{14} \mathrm{C}\right] \mathrm{TAC}$ to the rats. Since biliary secretion is not the major elimination route for large molecules, the radioactivity of ${ }^{14} \mathrm{C}$ could either be from degraded TAC or dmDNA31 released from TAC. As the liver plays a critical role in the elimination of dmDNA31 in rats, patients with hepatic impairment may lead to an accumulation of dmDNA31 in the body. Additional studies are needed to further evaluate the clinical relevance of our rat study.

In the bile and urine samples, unconjugated dmDNA31 (C7) in combination with $\mathrm{C} 6$ were identified as the major species/catabolites after intravenous administration of $\left[{ }^{14} \mathrm{C}\right] \mathrm{TAC}$. However, the concentrations of these catabolites in tissues and systemic circulation were low since most dmDNA31 was in the conjugated form after TAC administration. The results from our study suggest that TAC has a different metabolism/catabolism profile compared with smallmolecule antibiotics, and different clinical strategies may be needed to monitor its metabolism. Since dmDNA31 was reported to be a weak inhibitor of several cytochrome $\mathrm{P} 450$ enzymes with $\mathrm{IC}_{50}$ values ranging from 1 to $10 \mu \mathrm{M}$ (data not shown), and the PK of antibody-conjugated dmDNA31 is driven by its antibody component, the results from this study imply that the risk of DDIs should be relatively low.

In summary, we have characterized the tissue distribution, catabolism, and elimination of TAC, a novel modality against $S$. aureus infection, in rats using multiple approaches. Our study demonstrated that specific conjugation of the antibiotic dmDNA31 attained good linker stability in circulation and achieved sustained exposure in systemic circulation and tissues. Although many ADCs are under development for various disease indications, only a limited amount of absorption, distribution, metabolism, and elimination information is available for this complex therapeutic modality in the literature. Our work demonstrates that radiolabeling technology can be used to label different components of TAC to delineate the absorption, distribution, metabolism, and elimination properties of ADCs. This technique provides key information to help assess the risk of DDIs and the need for conducting clinical studies in a special population. This study also highlights the value of applying preclinical studies to support the clinical development of molecules with a similar modality and mechanism of action.

\section{Acknowledgments}

We would like to thank Elizabeth Torres, Jason Ho, and Konnie Urban from Genentech Inc. for animal studies. We would also like to thank Anshin BioSolutions Corp for editing this manuscript.

\section{Authorship Contributions}

Participated in research design: Yip, Lee, Saad, Ma, Khojasteh, Kamath, Shen.

Conducted experiment: Yip, Lee, Wong, Ma, Ljumanovic.

Performed data analysis: Cai, Yip, Lee, Ma.

Wrote or contributed to the writing of the manuscript: Cai, Yip, Shen.

\section{References}

Archer NK, Mazaitis MJ, Costerton JW, Leid JG, Powers ME, and Shirtliff ME (2011) Staphylococcus aureus biofilms: properties, regulation, and roles in human disease. Virulence 2: 445-459.

Barcia-Macay M, Seral C, Mingeot-Leclercq MP, Tulkens PM, and Van Bambeke F (2006) Pharmacodynamic evaluation of the intracellular activities of antibiotics against Staphylococcus aureus in a model of THP-1 macrophages. Antimicrob Agents Chemother 50:841-851.

Bassetti M, Righi E, Del Giacomo P, Sartor A, Ansaldi F, Trucchi C, Alicino C, Trecarichi EM, Spanu T, Paganino C, et al. (2018) Predictors of mortality with Staphylococcus aureus bacteremia in elderly adults. $J$ Am Geriatr Soc 66:1284-1289.

Boswell CA, Marik J, Elowson MJ, Reyes NA, Ulufatu S, Bumbaca D, Yip V, Mundo EE, Majidy N, Van Hoy M, et al. (2013) Enhanced tumor retention of a radiohalogen label for site-specific modification of antibodies. J Med Chem 56:9418-9426.

Chizzonite R, Truitt T, Podlaski FJ, Wolitzky AG, Quinn PM, Nunes P, Stern AS, and Gately MK (1991) IL-12: monoclonal antibodies specific for the 40-kDa subunit block receptor binding and biologic activity on activated human lymphoblasts. J Immunol 147:1548-1556.

Daghighi S, Sjollema J, Harapanahalli A, Dijkstra RJ, van der Mei HC, and Busscher HJ (2015) Influence of antibiotic pressure on bacterial bioluminescence, with emphasis on Staphylococcus aureus. Int J Antimicrob Agents 46:713-717.

Deng R, Bumbaca D, Pastuskovas CV, Boswell CA, West D, Cowan KJ, Chiu H, McBride J, Johnson C, Xin Y, et al. (2016) Preclinical pharmacokinetics, pharmacodynamics, tissue distribution, and tumor penetration of anti-PD-L1 monoclonal antibody, an immune checkpoint inhibitor. MAbs 8:593-603.

Deng R, Zhou C, Li D, Cai H, Sukumaran S, Carrasco-Triguero M, Saad O, Nazzal D, Lowe C Ramanujan S, et al. (2019) Preclinical and translational pharmacokinetics of a novel THIO$\mathrm{MAB}^{\mathrm{TM}}$ antibody-antibiotic conjugate against Staphylococcus aureus. MAbs 11:1162-1174. 
Fowler VG Jr., Nelson CL, McIntyre LM, Kreiswirth BN, Monk A, Archer GL, Federspiel J, Naidich S, Remortel B, Rude T, et al. (2007) Potential associations between hematogenous complications and bacterial genotype in Staphylococcus aureus infection. J Infect Dis 196: 738-747.

Junutula JR, Raab H, Clark S, Bhakta S, Leipold DD, Weir S, Chen Y, Simpson M, Tsai SP, Dennis MS, et al. (2008) Site-specific conjugation of a cytotoxic drug to an antibody improves the therapeutic index. Nat Biotechnol 26:925-932.

Kamath AV, Yip V, Gupta P, Boswell CA, Bumbaca D, Haughney P, Castro J, Tsai SP, Pacheco G, Ross S, et al. (2014) Dose dependent pharmacokinetics, tissue distribution, and anti-tumor efficacy of a humanized monoclonal antibody against DLL4 in mice. MAbs 6 $1631-1637$.

Laffont CM, Toutain PL, Alvinerie M, and Bousquet-Mélou A (2002) Intestinal secretion is a major route for parent ivermectin elimination in the rat. Drug Metab Dispos 30:626-630.

Lehar SM, Pillow T, Xu M, Staben L, Kajihara KK, Vandlen R, DePalatis L, Raab H, Hazenbos WL, Morisaki JH, et al. (2015) Novel antibody-antibiotic conjugate eliminates intracellular S. aureus. Nature 527:323-328.

Levine DP, Fromm BS, and Reddy BR (1991) Slow response to vancomycin or vancomycin plus rifampin in methicillin-resistant Staphylococcus aureus endocarditis. Ann Intern Med 115 674-680.

Li Z, Krippendorff BF, Sharma S, Walz AC, Lavé T, and Shah DK (2016) Influence of molecular size on tissue distribution of antibody fragments. MAbs 8:113-119.

Liu C, Bayer A, Cosgrove SE, Daum RS, Fridkin SK, Gorwitz RJ, Kaplan SL, Karchmer AW, Levine DP, Murray BE, et al.; Infectious Diseases Society of America (2011) Clinical practice guidelines by the infectious diseases society of america for the treatment of methicillin-resistant Staphylococcus aureus infections in adults and children. Clin Infect Dis 52:e18-e55.

Pastuskovas CV, Mundo EE, Williams SP, Nayak TK, Ho J, Ulufatu S, Clark S, Ross S, Cheng E, Parsons-Reponte K, et al. (2012) Effects of anti-VEGF on pharmacokinetics, biodistribution, and tumor penetration of trastuzumab in a preclinical breast cancer model. Mol Cancer Ther 11: $752-762$.

Shen BQ, Bumbaca D, Saad O, Yue Q, Pastuskovas CV, Khojasteh SC, Tibbitts J, Kaur S, Wang B, Chu YW, et al. (2012) Catabolic fate and pharmacokinetic characterization of trastuzumab emtansine (T-DM1): an emphasis on preclinical and clinical catabolism. Curr Drug Metab 13:901-910.

Thwaites GE and Gant V (2011) Are bloodstream leukocytes Trojan Horses for the metastasis of Staphylococcus aureus? Nat Rev Microbiol 9:215-222.

van Hal SJ, Jensen SO, Vaska VL, Espedido BA, Paterson DL, and Gosbell IB (2012) Predictors of mortality in Staphylococcus aureus Bacteremia. Clin Microbiol Rev 25:362-386.

Zhang D, He K, Raghavan N, Wang L, Mitroka J, Maxwell BD, Knabb RM, Frost C, Schuster A, Hao F, et al. (2009) Comparative metabolism of 14C-labeled apixaban in mice, rats, rabbits, dogs, and humans. Drug Metab Dispos 37:1738-1748.

Zhou C, Cai H, Baruch A, Lewin-Koh N, Yang M, Guo F, Xu D, Deng R, Hazenbos W, and Kamath AV (2019) Sustained activity of novel THIOMAB antibody-antibiotic conjugate against Staphylococcus aureus in a mouse model: longitudinal pharmacodynamic assessment by bioluminescence imaging. PLoS One 14:e224096.

Zhou C, Lehar S, Gutierrez J, Rosenberger CM, Ljumanovic N, Dinoso J, Koppada N, Hong K, Baruch A, Carrasco-Triguero M, et al. (2016) Pharmacokinetics and pharmacodynamics of DSTA4637A: a novel THIOMAB ${ }^{\mathrm{TM}}$ antibody antibiotic conjugate against Staphylococcus aureus in mice. MAbs 8:1612-1619.

Address correspondence to: Ben-Quan Shen, Preclinical and Translational Pharmacokinetics and Pharmacodynamics,, Genentech Inc., 1 DNA Way, South San Francisco, CA 94080. E-mail: shen.ben@gene.com 